\title{
Efficiency of GnRH-Loaded Chitosan Nanoparticles for Inducing LH Secretion and Fertile Ovulations in Protocols for Artificial Insemination in Rabbit Does
}

\author{
Eman M. Hassanein ${ }^{1}$, Nesrein M. Hashem ${ }^{1, *(D)}$, Kheir El-Din M. El-Azrak ${ }^{1}$, Antonio Gonzalez-Bulnes ${ }^{2,3, *}$, \\ Gamal A. Hassan ${ }^{1}$ and Mohamed H. Salem ${ }^{1}$
}

1 Animal and Fish Production Department, Faculty of Agriculture, Alexandria University, Alexandria 21545, Egypt; eman.mostafa1177@yahoo.com (E.M.H.);

kheir_elazrak@yahoo.com (K.E.-D.M.E.-A.); gamaleldeen.hassan@alexu.edu.eg (G.A.H.); mhsalem15@yahoo.com (M.H.S.)

2 Departamento de Reproduccion Animal, INIA, Avda. Puerta de Hierro s/n., 28040 Madrid, Spain

3 Departamento de Produccion y Sanidad Animal, Facultad de Veterinaria, Universidad Cardenal Herrera-CEU, CEU Universities, C/ Tirant lo Blanc, 7, 46115 Alfara del Patriarca, Valencia, Spain

* Correspondence: nesreen.hashem@alexu.edu.eg (N.M.H.); antonio.gonzalezbulnes@uchceu.es (A.G.-B.)

check for updates

Citation: Hassanein, E.M.; Hashem, N.M.; El-Azrak, K.E.-D.M.;

Gonzalez-Bulnes, A.; Hassan, G.A.;

Salem, M.H. Efficiency of

GnRH-Loaded Chitosan

Nanoparticles for Inducing LH

Secretion and Fertile Ovulations in

Protocols for Artificial Insemination

in Rabbit Does. Animals 2021, 11, 440.

https://doi.org/10.3390/ani11020440

Academic Editors: Juan Vicente and Bermejo Delgado

Received: 11 January 2021

Accepted: 2 February 2021

Published: 8 February 2021

Publisher's Note: MDPI stays neutral with regard to jurisdictional claims in published maps and institutional affiliations.

Copyright: (c) 2021 by the authors. Licensee MDPI, Basel, Switzerland. This article is an open access article distributed under the terms and conditions of the Creative Commons Attribution (CC BY) license (https:// creativecommons.org/licenses/by/ $4.0 /)$.
Simple Summary: Nano-drug delivery systems can be employed for improving ovulation induction prior to artificial insemination (AI) in rabbits. In this study, different routes of administration and different doses of GnRH-loaded chitosan nanoparticles (GnRH-ChNPs) were assessed for inducing ovulation in rabbits, proving their usefulness to reduce the GnRH dose and animal handling and improving AI outcomes. The use of GnRH-ChNPs allows for the reduction of the conventional intramuscular GnRH dose to half without compromising fertility. However, the addition of GnRHChNPs to semen extenders, although successfully inducing ovulation, has negative impacts on fertility. Thus, more studies are needed to allow further adjustments.

Abstract: Gonadotropin-releasing hormone (GnRH)-loaded chitosan nanoparticles (GnRH-ChNPs) were used at different doses and routes of administration to induce ovulation in rabbits as an attempt to improve artificial insemination (AI) procedures and outcomes. In this study, the characteristics (size, polydispersity, loading efficiency, and zeta-potential) of GnRH-ChNPs and the GnRH release pattern were determined in an in vitro study. A first in vivo study assessed the pituitary and ovarian response to different $\mathrm{GnRH}-\mathrm{ChNPs}$ doses and routes of administration (two i.m. doses, Group HM = $0.4 \mu \mathrm{g}$ and Group QM $=0.2 \mu \mathrm{g}$, and two intravaginal doses, Group HV $=4 \mu \mathrm{g}$ and Group QV $=2 \mu \mathrm{g}$ ) against a control group $(\mathrm{C})$ receiving bare $\mathrm{GnRH}(0.8 \mu \mathrm{g})$. The HM, QM, and HV treatments induced an earlier LH-surge $(90 \mathrm{~min})$ than that observed in group C (120 min), whilst the QV treatment failed to induce such LH surge. The number of ovulation points was similar among treatments, except for the QV treatment (no ovulation points). A second in vivo study was consequently developed to determine the hormonal (progesterone, $\mathrm{P}_{4}$, and estradiol, $\mathrm{E}_{2}$ ) profile and pregnancy outcomes of both $\mathrm{HM}$ and HV treatments against group $\mathrm{C}$. The treatment HM, but not the treatment HV, showed adequate $\mathrm{P}_{4}$ and $\mathrm{E}_{2}$ concentrations, conception and parturition rates, litter size, litter weight, and viability rate at birth. Overall, the use of GnRH-ChNPs allows for a reduction in the conventional intramuscular GnRH dose to half without compromising fertility. However, the addition of GnRHChNPs to semen extenders, although successfully inducing ovulation, has negative impacts on fertility. Thus, more studies are needed to explore this point and allow further adjustments.

Keywords: artificial-insemination; GnRH; nanotechnology; ovulation; rabbit

\section{Introduction}

The occurrence of external stimulation during mating (neurohormonal reflex) is required to evoke the gonadotropin-releasing hormone (GnRH)-dependent luteinizing hor- 
mone (LH) surge, and consequently ovulation, in non-spontaneously ovulating species like the rabbit [1]. This biological event plays a crucial limiting role for the successful application of assisted reproductive techniques such as artificial insemination (AI) because, in the absence of the male, ovulation needs to be induced by artificial hormonal stimulation. Hence, the induction of ovulation in routine AI protocols is usually achieved by the administration of either $\mathrm{GnRH}$ or $\mathrm{LH}$ or other gonadotrophins with LH activity (i.e., equine chorionic gonadotrophin, eCG, or human chorionic gonadotrophin, hCG). The $\mathrm{GnRH}$ analogues (such as gonadorelin, lecirelin, triptorelin, or buserelin) are the most recommended compounds because they have additional biological advantages and the possibility of repeated treatments without developing specific antibodies [2].

Currently, GnRH is included in semen extenders to be directly administered to the doe via the seminal dose, which improves animal management and welfare [2]. Certainly, the successful implementation of the intravaginal route in protocols for ovulation induction may minimize animal distress and staff workload when compared to traditional protocols via intramuscular doses. However, the enzymatic proteolytic activity of seminal plasma and vaginal fluids and the biological barriers for mucosal permeation may limit the efficiency of such protocols.

In addition, GnRH has a short half-life time in blood circulation, 2-4 min, because it is rapidly degraded by peptidases and cleared by glomerular filtration [3], which limits both its biological activity and sustained action. Consequently, a first approach for improving the efficiency of the treatment is to increase the dose or the activity of the GnRH analogue. However, doses more than ten to fifteen-fold higher are needed (about 8 and $16 \mu \mathrm{g}$ buserelin/seminal dose), which constitutes a potential health risk for workers and significantly increases the cost-efficiency of the protocols [4].

A promising alternative may be based on the use of nano-drug delivery systems. Nano-drug delivery systems have been optimized to extend the half-life time of the compound to improve its passage across endothelial or epithelial barriers into blood or lymph circulation and to sustain its delivery to the target sites. Consequently, overcoming these biological barriers can improve cellular uptake and therefore lower doses of drugs/hormones may be used [5-9]. Hence, nano-drug systems for hormonal treatments (e.g., GnRH for ovulation induction) may benefit many biotechnological assisted reproductive techniques in the livestock field (e.g., AI [5]). However, there is a scarcity of data regarding both hormone bioactivity and animal performance when GnRH is used in nano-formula, although previous results are promising. To date, chitosan-dextran sulfate $\mathrm{GnRH}$ (buserelin acetate) nanoparticles have been added to seminal doses of rabbits [10], allowing the GnRH dose to be reduced to half the conventional dose without affecting the fertility of the does. Moreover, the results of a trial performed with the administration of chitosan-tripolyphosphate (TPP)-conjugated GnRH nanoparticles in goats indicate that the GnRH dose may be even reduced three- to four-fold without affecting fertility and prolificacy [11].

The practical application of such protocols makes necessary extensive studies on technical and physiological features that may limit the efficiency and final outcomes of treatments involving GnRH-loaded nanoparticles (fabrication, route of administration, bioavailability and hormonal balance). Therefore, the present study aimed to set the basis and evaluate the feasibility and efficiency of GnRH nanoparticles for inducing ovulation in rabbits. Three consecutive experiments (first an in vitro approach and afterward, two in vivo trials) were performed to (1) manufacture and evaluate the physicochemical properties and release patterns of GnRH-loaded chitosan nanoparticles, and (2) determine the ovarian response, hormonal balance, and reproductive performance of does after ovulation induction with different doses and administration routes (intramuscular vs. intravaginal) of such GnRH nanoparticles. 


\section{Materials and Methods}

\subsection{Manufacturing of Gonadotropin-Releasing Hormone (GnRH)-Loaded Chitosan Nanoparticles}

Chitosan (chitosan extra pure; with a degree of deacetylation $>85 \%$; molecular weight = 300-350 KD; Alpha Chemika, Mubia, India) and sodium tripolyphosphate (TPP; Thermo Fisher $\mathrm{GmbH}$, Kandel, Germany) were used in the fabrication of a nano-carrier polymer following the steps of the ionic gelation method [10-12]. Briefly, chitosan (0.1\%, wt/vol) was vigorously stirred in an aqueous acidic solution $(1 \%, \mathrm{wt} / \mathrm{vol})$ to obtain polymeric chitosan cations. An aqueous solution of TPP $(0.1 \mathrm{~g} / \mathrm{dL})$ was also prepared. Afterward, the chitosan-TPP nanoparticles were prepared by slowly dropping the TPP solution into a chitosan solution (chitosan to TPP weight ratio was 2:1) under constant magnetic stirring $(800 \mathrm{rpm})$ for $2 \mathrm{~h}$ at room temperature. The $\mathrm{pH}$ of the chitosan-TPP solution was adjusted to 5.5 and then stored in the refrigerator before exposure to any analysis or application. GnRH-loaded chitosan nanoparticles (GnRH-ChNPs) were prepared by dripping-wise the hormone $\left(\mathrm{GnRH}\right.$; Receptal ${ }^{\circledR}, \mathrm{MSD}$, Intervet International GmbH, Unterschleißheim, Germany) solution to the fabricated ChNPs in a ratio of 1:1. The mixture was adjusted to a pH of 6.5 and after that stirred gently at $800 \mathrm{rpm}$ for $60 \mathrm{~min}$ at room temperature and incubated overnight to allow the hormonal adsorption on the surface of the nanoparticles.

\subsection{In Vitro Assessment of the Physicochemical Properties and Release Patterns of GnRH-Loaded Nanoparticles}

Particle size, zeta potential, and size distribution (polydispersity index, PdI) of the free ChNPs and GnRH-ChNPs were measured using a Zetasizer instrument (Malvern Instruments, Malvern, UK), which is based on dynamic light scattering (DLS) techniques. The samples were analyzed in triplicate and the average value $( \pm S D)$ of each parameter was calculated. The functional groups of chitosan $(\mathrm{Ch}), \mathrm{ChNPs}$, and GnRH-ChNPs were identified by Fourier transform infrared spectrophotometer (FTIR, a Perkins Elmer 1600, USA) in the range from 4000 to $400 / \mathrm{cm}$ using potassium bromide discs ( $\mathrm{KBr})(5 \mathrm{mg}$ of particles, $100 \mathrm{mg} \mathrm{KBr}$ pellets). Morphological characteristics of the free ChNPs and GnRHChNPs were examined using transmission electron microscope (TEM; JEOL JEM-1400, 120 kV, Peabody, MA, USA). Freshly fabricated ChNPs and GnRH-ChNPs solutions were diluted with deionized water with adjusted $\mathrm{pH}$ close to neutral. A one-drop sample was placed on a carbon-coated film 300 mesh copper grid and was left for 10 min until air-dried. The sample was stained with $1 \mathrm{M}$ uranyl acetate solution for $1.5 \mathrm{~min}$ at $7^{\circ} \mathrm{C}$ and any excess uranyl acetate was removed with filter paper before viewing on the TEM at magnification $\times 20,000$.

The hormonal loading efficiency (LE\%) was determined by the separation of the nanoparticles from the aqueous medium by centrifugation at $1200 \times g$ at $4{ }^{\circ} \mathrm{C}$ for $20 \mathrm{~min}$. The amount of free hormone in the supernatant of GnRH-ChNPs solution was measured using UV spectrophotometry at a wavelength of $280 \mathrm{~nm}$ (Optizen Pop, Mecasys Co. Ltd., Daejeon, Korea) and using the supernatant of ChNPs solution as a blank [13]. Afterward, LE\% was calculated as ([initial GnRH concentration - free GnRH concentration]/initial GnRH concentration $\times 100)$.

The assessment of release patterns was carried out for $48 \mathrm{~h}$ to plot the kinetic release profile of GnRH from ChNPs according to the method described by Dounighi and coworkers [13]. In brief, a pre-weighed sample of GnRH-ChNPs was divided into three aliquots and dissolved in equal volumes of phosphate buffer solution (PBS; pH 7.4). The samples were then incubated at $37^{\circ} \mathrm{C}$ in a shaker adjusted at $600 \mathrm{rpm}$ for $48 \mathrm{~h}$. At allocated time intervals $(0.5,1,2,4,6,10,12,24,48 \mathrm{~h})$, the samples were removed and centrifuged at $14,000 \mathrm{rpm}$ and $4{ }^{\circ} \mathrm{C}$ for $20 \mathrm{~min}$. The concentration of free $\mathrm{GnRH}$ released into the supernatant was evaluated by spectrophotometry at the $280 \mathrm{~nm}$ wavelength (Optizen pop, Mecasys Co. Ltd. Daejeon, Korea). The amount of GnRH was calculated using non-loaded nanoparticles as a blank and then LE\% was determined as previously described. 


\subsection{In vivo Assessment of the Reproductive Response of Does Treated with GnRH-Loaded Nanoparticles}

\subsubsection{Animals and Ethic Statement}

A total of 62 female rabbits were used. The experiments were carried out at the Laboratory of Rabbit Physiology Research, Faculty of Agriculture, Alexandria University, Egypt $\left(31^{\circ} 20^{\prime} \mathrm{N}, 30^{\circ} \mathrm{E}\right)$. The does were individually housed in standard wire cage batteries $(40 \times 50 \times 35 \mathrm{~cm})$ at the same rabbitry $\left(10.97 \pm 0.36 \mathrm{~h}\right.$ daylight length, $19.85 \pm 1.03{ }^{\circ} \mathrm{C}$ temperature and $74.92 \pm 2.543 \%$ relative humidity). Does were fed ad-libitum with a pelleted diet, containing $17.73 \%$ crude protein and $68.96 \% \mathrm{TDN}$ ) and had free access to water. All animals were handled according to the principles of animal care published by the European Union Directive 2010/63/UE on the protection of animals used for research and, in agreement, the experimental procedures used were previously assessed and approved by the INIA Committee of Ethics in Animal Research (report CEEA2014/087).

\subsubsection{Trial 1. Patterns of LH Secretion, Ovulatory Efficiency, and Early Fertility}

Twenty adult nulliparous rabbit does (5-5.5 months-old and $2.82 \pm 0.21 \mathrm{~kg}$ of bodyweight) were treated for estrus synchronization with 25 IU of eCG (Gonaser ${ }^{\circledR}$, Hipra, Girona, Spain) [14] and $48 \mathrm{~h}$ later, does were subjected to one of the following five ovulation induction treatments: a control conventional i.m. protocol $(0.8 \mu \mathrm{g}$ of $\mathrm{GnRH}$ in distilled water; C-treatment) and four protocols using GnRH-ChNPs with half i.m. dose (0.4 $\mu$ g. GnRH-ChNPs; HM-treatment), quarter i.m. dose (0.2 $\mu$ g i.m. GnRH-ChNPs; QM-treatment), half vaginal dose (4 $\mu \mathrm{g}$ vs. GnRH-ChNPs; HV-treatment), and quarter vaginal dose ( $2 \mu \mathrm{g}$ vs. GnRH-ChNPs; QV-treatment). Females in C, HM, and HV treatments were immediately inseminated artificially with $0.3 \mathrm{~mL}$ diluted semen $\left(30 \times 10^{6}\right.$ sperm/insemination). Females in HV and QV treatments were inseminated, at the same time, using the same seminal dose, but supplemented with the corresponding GnRHChNPs. Semen samples used for AI were collected from five fertile rabbit bucks by using an artificial vagina and a teaser doe. The quality of semen was evaluated, and only semen samples fulfilling quality criteria were used for AI [15]. The doses of GnRH-ChNPs were based on the findings of previous studies, where the dose of $0.8 \mu \mathrm{g} \mathrm{GnRH}$ is the conventional dose in intramuscular treatment and dose of $8 \mu \mathrm{g} \mathrm{GnRH}$ is the conventional dose in intravaginal treatment $[4,11]$. The schematic diagram of the experiment is presented in Figure 1.

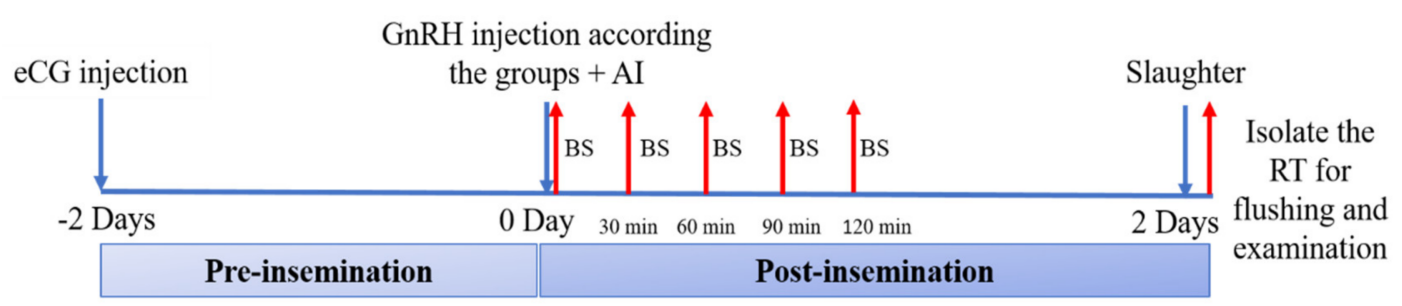

Figure 1. Experimental planning of trial 1, aiming to determine the effect of gonadotrophin-releasing hormone (GnRH) in different doses and routes of administration on LH secretion (by means of successive blood samples; BS) and presence of oocytes/embryos in the reproductive tract, RT, at day 2 after artificial insemination (AI).

The assessment of the patterns of LH secretion was performed on blood samples collected from the marginal ear vein of each doe with non-heparinized tubes at 0 (time of insemination) $30,60,90$, and $120 \mathrm{~min}$ post-insemination. The samples were centrifuged at $700 \times g$ for $20 \mathrm{~min}$ to obtain serum, which was stored at $-20^{\circ} \mathrm{C}$ until analysis. Then, the serum LH concentration was determined using an enzyme immunoassay commercial kit (Cusabio Biotech, Hubei, China). The assay sensitivity was $0.35 \mathrm{mIU} / \mathrm{mL}$ and intra- and inter-assay coefficients of variation were $8 \%$ and $10 \%$, respectively.

Afterward, all females were sacrificed $48 \mathrm{~h}$ post-insemination and the reproductive tracts were immediately obtained. The ovaries were dissected for determining the number 
of total ovarian follicles (clear visible follicles) and the number of ovulatory points (ovulated follicles), as previously described [14]. The oviducts were flushed with $15 \mathrm{~mL}$ of phosphate buffer solution (PBS) containing $0.2 \%$ of bovine serum albumin (BSA, Sigma-Aldrich, Madrid, Spain) to assess the number of embryos and their development stage and the number of non-fertilized oocytes with a binocular microscope (Olympus Optical Co. Ltd., Tokyo, Japan).

\subsubsection{Trial 2. Fertility and Productive Traits}

Forty-two adult nulliparous rabbit does (5-5.5 months-old and $2.41 \pm 0.21 \mathrm{~kg}$ of bodyweight) were treated for ovulation induction and AI as described in trial 1 but, according to the results of such experiment, only three treatments were used (C, HM, and HV; $n=$ 14/treatment). The schematic diagram of the experiment is presented in Figure 2.

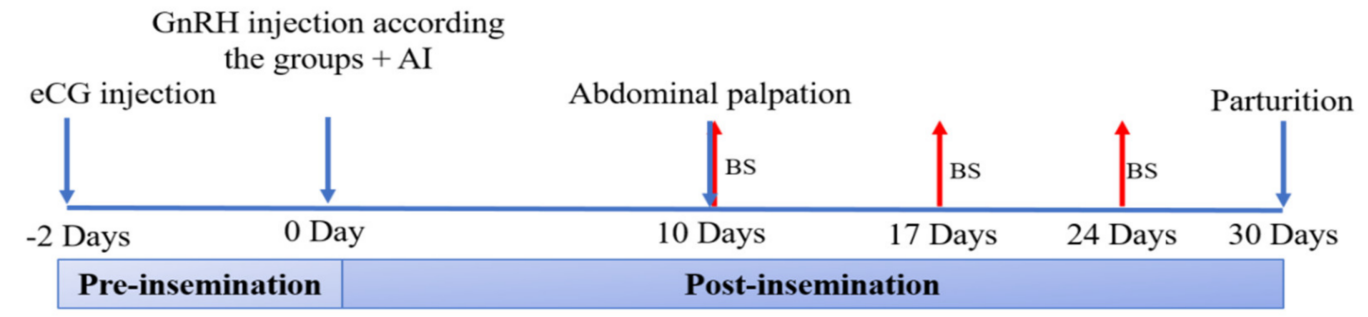

Figure 2. Experimental planning of trial 2, aiming to determine the effect of gonadotrophin-releasing hormone (GnRH) in different routes of administration on hormonal patterns (by means of successive blood samples; BS) and fertility and reproductive traits after artificial insemination (AI).

Pregnancy diagnosis was performed by abdominal palpation at Day 10 after AI. Blood samples were collected at days 10,17, and 24 of pregnancy, as previously described, to determine the concentrations of progesterone $\left(\mathrm{P}_{4}\right)$ and estradiol $\left(\mathrm{E}_{2}\right)$ by using commercial enzyme immunoassay kits (Monobind Inc. Lake Forest, California, CA, USA.). The assay sensitivities were $0.105 \mathrm{ng} / \mathrm{mL}$ for $\mathrm{P}_{4}$ and $8.2 \mathrm{pg} / \mathrm{mL}$ for $\mathrm{E}_{2}$, while intra- and inter-assay coefficients of variation were $8.4 \%$ and $7.6 \%$ for $\mathrm{P}_{4}$ and $8.6 \%$ and $<5.6 \%$ for $\mathrm{E}_{2}$.

Fertility and productive traits were recorded in terms of conception rate ([number of pregnant does on Day 10/total number of inseminated does] $\times 100$ ), parturition rate ([number of delivering does/total number of inseminated does] $\times 100$ ), abortion rate ([number of aborted does/number of pregnant does] $\times 100$ ), litter size ([number of kits at birth/number of delivering does]) and viability rate ([number of live kits at birth/litter size at birth] $\times 100$ ).

\subsection{Statistical Analysis}

Total numbers of visible and ovulated follicles, total numbers of oocytes, and embryos were subjected to square root transformation to approximate normal distribution before subjecting to ANOVA. Data observed once a time (results of the first trial 1) including weights of different reproductive organs, numbers of ovarian follicles, ovulation points, oocytes, and embryos were analyzed by a generalized linear model (GLM) of SAS [16]. The same procedure was used for litter size weight and viability variables in the second trial. Repeated measurements including concentrations of serum LH, $\mathrm{P}_{4}$, and $\mathrm{E}_{2}$ were analyzed using the MIXED procedure of SAS. The statistical model included the fixed effect of treatment, time of sampling/data collection, and the interactions as well as the random effect of an individual female were considered. Categorical data, expressed as percentages (conception, parturition, and abortion rates) were analyzed using a chi-square test (PROC FREQ). All results were presented as least square mean \pm standard error ( \pm S.E.M.). The statistically significant differences were accepted from $p<0.05$ ). 


\section{Results}

3.1. In Vitro Assessment of the Physicochemical Properties and Release Patterns of GnRH-Loaded Nanoparticles

Physicochemical characteristics and loading efficiency of GnRH-ChNPs are shown in Table 1. The loading efficiency of GnRH by ChNPs was $90 \%$ and the average size, PdI and zeta potential of ChNPs and GnRH-ChNPs were $95.19 \pm 1.9 \mathrm{~nm}$ vs. $212 \pm 2.69 \mathrm{~nm}, 0.165$ vs. 0.295 , and +34.0 vs. $+8.0 \mathrm{mV}$, respectively. The FTIR showed that the $\mathrm{Ch}$ spectra exerted peaks at $3458.3 \mathrm{~cm}^{-1}, 2924.3 \mathrm{~cm}^{-1}, 1645.5 \mathrm{~cm}^{-1}, 1419.1 \mathrm{~cm}^{-1}, 1314.8 \mathrm{~cm}^{-1}, 1572.05 \mathrm{~cm}^{-1}$, and $1077 \mathrm{~cm}^{-1}$, which belong to the following functional groups: hydrogen-bond, $\mathrm{O}-\mathrm{H} ; \mathrm{C}-\mathrm{H}$ bond in pyranose rings; $\mathrm{C}=\mathrm{O}$ in $\mathrm{NHCOCH}_{3} ; \mathrm{C}-\mathrm{H}$ in $\mathrm{CH}_{2} \mathrm{OH} ; \mathrm{C}-\mathrm{N}$ stretching vibration of type II amine; $\mathrm{N}-\mathrm{H}$ bond; and $\mathrm{C}-\mathrm{O}-\mathrm{C}$ in glucosidic-linkages. Addition of TPP to chitosan solution resulted in the disappearance of $\mathrm{C}-\mathrm{H}$ and $\mathrm{N}-\mathrm{H}$ functional groups, indicating binding of these groups with phosphate groups in TPP. Addition of GnRH to ChNPs resulted in shifts for the remaining functional groups identified in Ch spectra (Figure 3).

Table 1. Particle size, polydispersity index (PdI), zeta potential, and loading efficiency of chitosan nanoparticles (ChNPs) and GnRH-loaded chitosan nanoparticles (GnRH-ChNPs).

\begin{tabular}{ccccc}
\hline Nanoparticles. & $\begin{array}{c}\text { Particle Size } \\
(\mathbf{n m})\end{array}$ & PdI & $\begin{array}{c}\text { Zeta Potential } \\
\text { (mV) }\end{array}$ & $\begin{array}{c}\text { Loading } \\
\text { Efficiency (\%) }\end{array}$ \\
\hline ChNPs & $95.19 \pm 1.90$ & 0.165 & +34.0 & - \\
GnRH-ChNPs & $212 \pm 2.69$ & 0.295 & +8.0 & 90 \\
\hline
\end{tabular}

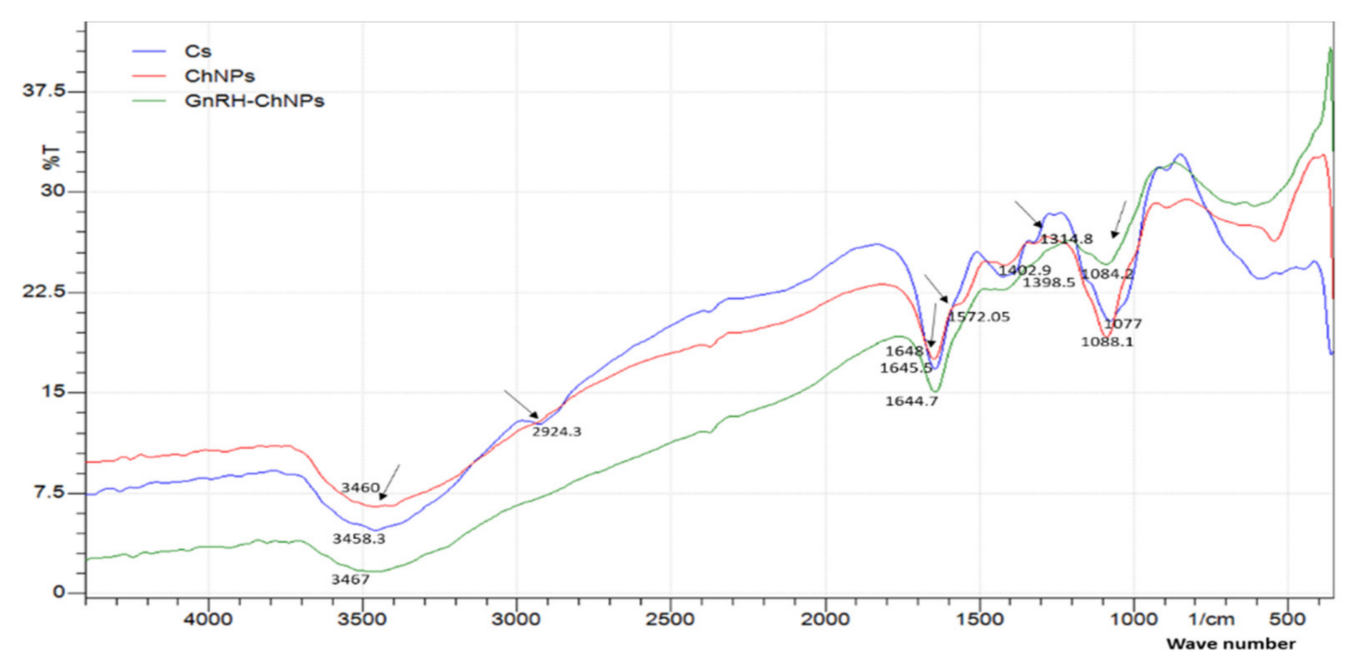

Figure 3. Fourier transform infrared (FTIR) spectra of chitosan (Ch), chitosan-TPP nanoparticles (ChNPs).

The images of ChNPs under the transmission electron microscope showed spherical nanoparticles with smooth surfaces and a diameter of about $100 \mathrm{~nm}$ and, after GnRH loading, the diameter of GnRH-ChNPs reached $200 \mathrm{~nm}$ with high agglomerating appearance (Figure 4). 

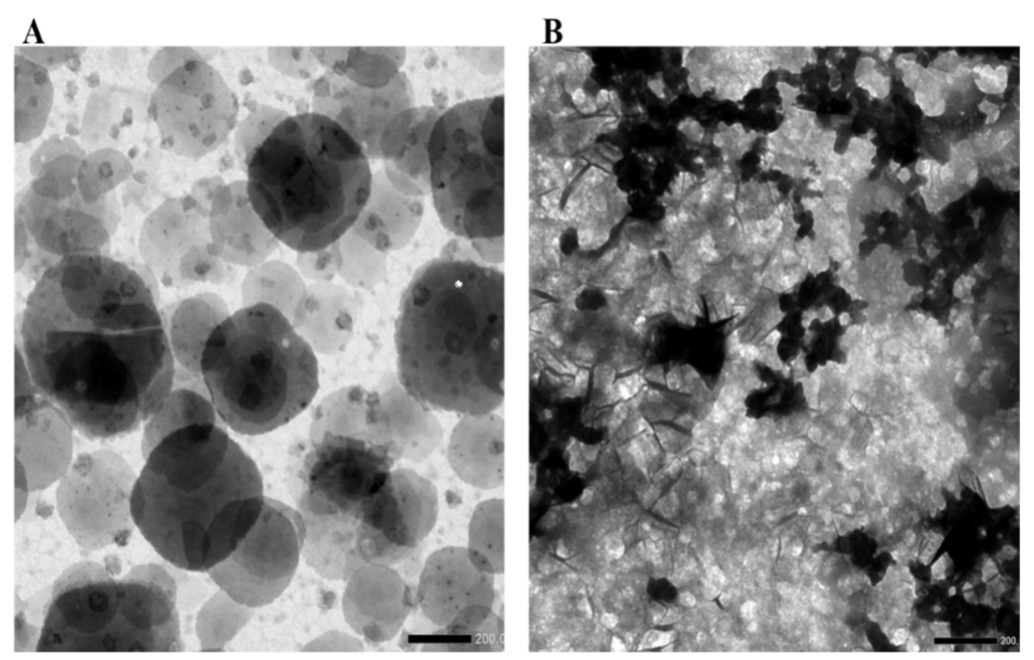

Figure 4. Transmission electron microscope image of (A) chitosan-TPP nanoparticles and (B) GnRHloaded chitosan nanoparticles at a magnification $\times 20,000$ and $25^{\circ} \mathrm{C}$.

The release profile of GnRH-ChNPs showed that the initial surge release of GnRH was about $50 \%$ at the first $10 \mathrm{~h}$ of incubation time, followed by a slow release of residual concentration during the subsequent $20 \mathrm{~h}$. The release of the almost loaded hormone (about $99 \%$ ) from ChNPs was after $30 \mathrm{~h}$ and remained steady up to $20 \mathrm{~h}$ later (Figure 5).

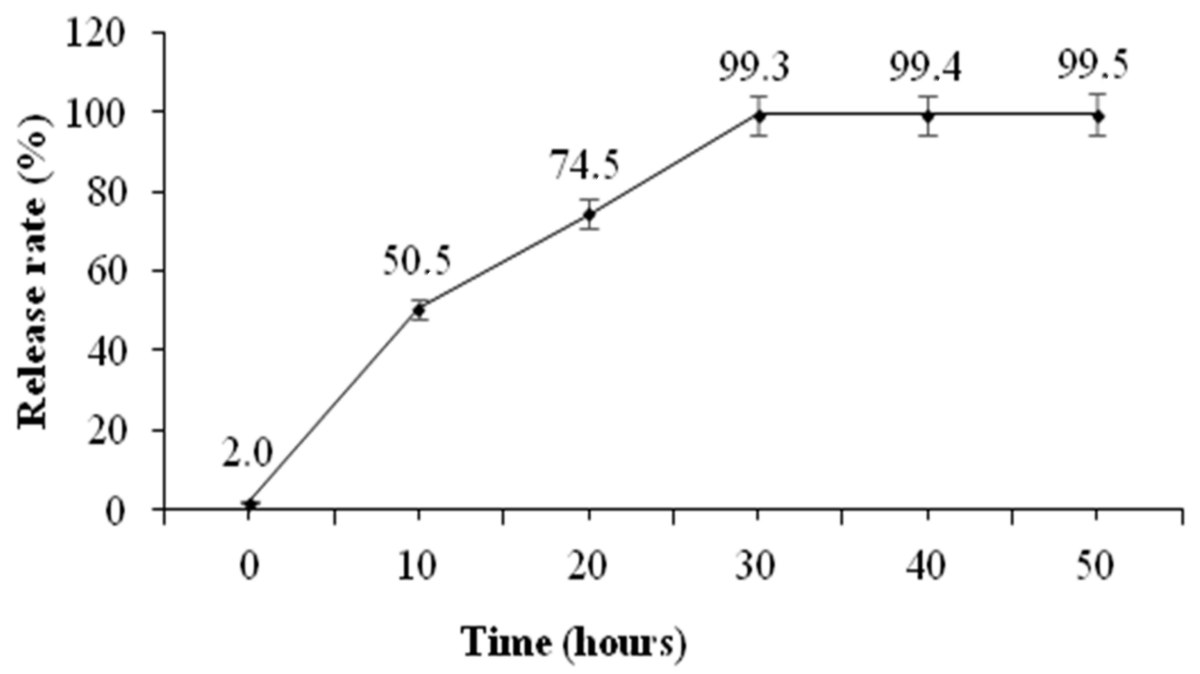

Figure 5. Mean ( \pm S.E.M.) percentage of over-time release of gonadotropin-releasing hormone $(\mathrm{GnRH})$ from GnRH-loaded chitosan nanoparticles.

3.2. In Vivo Assessment of Patterns of LH Secretion, Ovulatory Efficiency, and Early Fertility in Does Treated with GnRH-Loaded Nanoparticles

Figure 6 depicts the effect of different doses and routes of GnRH-ChNPs on serum LH concentrations at $0,30,60,90$, and $120 \mathrm{~min}$. There were no significant effects on overall mean LH concentrations but on timing of the preovulatory LH surge. The groups HM, QM, and HV showed an earlier LH surge (90 min vs. $120 \mathrm{~min}$ post-insemination in the treatment $C ; p<0.05)$, but the group QV failed to induce LH surge with LH concentrations remaining stable. 


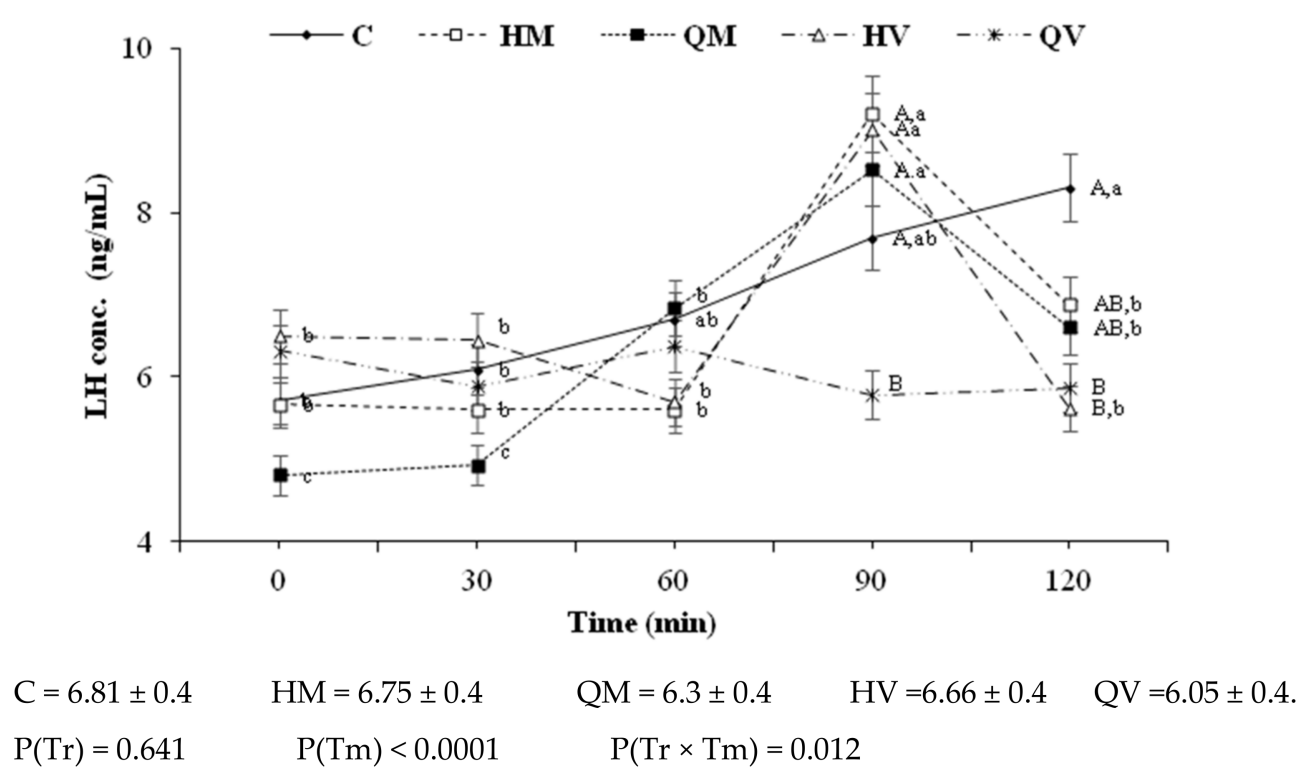

Figure 6. Changes over time in mean ( \pm S.E.M.) serum LH concentrations in rabbit does receiving two i.m. doses $(\mathrm{HM}=0.4 \mu \mathrm{g}$ and $\mathrm{QM}=0.2 \mu \mathrm{g})$ or two intravaginal doses $(\mathrm{HV}=4 \mu \mathrm{g}$ and $\mathrm{QV}=$ $2 \mu \mathrm{g})$ of $\mathrm{GnRH}-\mathrm{ChNPs}$ or bare $\mathrm{GnRH}(\mathrm{C}=0.8 \mu \mathrm{g})$. Overall values are included below the figure. $\mathrm{P}(\mathrm{Tr})$ accounts for treatment effects, $\mathrm{P}(\mathrm{Tm})$ for time effects, and $\mathrm{P}(\mathrm{Tr} \times \mathrm{Tm})$ for their interactions. Different uppercase and lowercase superscript letters denote significant differences $(p<0.05)$ between or within treatments, respectively.

All groups (HM, QM, HV, and QV) significantly increased the number of total ovarian follicles when compared to group $\mathrm{C}(p<0.05$; Table 2$)$. The number of total ovarian follicles was significantly lower in group HM, intermediate in groups $Q M$ and $Q V$, and higher in group HV $(p<0.05)$. There were no significant differences in the number of ovulation points among groups, except for group $\mathrm{QV}$, which showed no ovulation points.

Table 2. Ovarian structure and developmental stages of embryos collected $48 \mathrm{~h}$ post-insemination from rabbit does that received two intramuscular doses $(\mathrm{HM}=0.4 \mu \mathrm{g}$ and $\mathrm{QM}=0.2 \mu \mathrm{g})$ or two intravaginal doses $(\mathrm{HV}=4 \mu \mathrm{g}$ and $\mathrm{QV}=2 \mu \mathrm{g})$ of $\mathrm{GnRH}-\mathrm{ChNPs}$ compared to control rabbit does that received bare $\mathrm{GnRH}(0.8 \mu \mathrm{g})$.

\begin{tabular}{|c|c|c|c|c|c|c|}
\hline \multirow{2}{*}{ Variables } & \multicolumn{5}{|c|}{ Groups ( $n=4$ Does/Group) } & \multirow{2}{*}{$p$-Value } \\
\hline & $\mathrm{C}$ & HM & QM & HV & QV & \\
\hline \multicolumn{7}{|c|}{ Ovarian structure (mean \pm S.E.M.) } \\
\hline $\begin{array}{l}\text { Total ovarian } \\
\text { follicles }\end{array}$ & $15.5 \pm 1.0^{c}$ & $33.0 \pm 3.6^{b}$ & $36.5 \pm 0.9^{a b}$ & $40.2 \pm 0.2^{\mathrm{a}}$ & $36.5 \pm 2.0^{\mathrm{ab}}$ & 0.0001 \\
\hline Ovulation points & $6.3 \pm 0.9^{\mathrm{a}}$ & $9.3 \pm 1.2^{\mathrm{a}}$ & $6.0 \pm 1.2^{\mathrm{a}}$ & $8.8 \pm 1.2^{\mathrm{a}}$ & $0.00 \pm 0.00^{\mathrm{b}}$ & 0.001 \\
\hline Total embryos & $4.0 \pm 0.7^{b}$ & $6.2 \pm 0.9^{\mathrm{a}}$ & $5.2 \pm 1.4^{\mathrm{ab}}$ & $8.0 \pm 0.9^{\mathrm{a}}$ & $0.00 \pm 0.00^{c}$ & 0.001 \\
\hline Non-fertilized ova & $0.25 \pm 0.3$ & $0.00 \pm 0.0$ & $0.00 \pm 0.0$ & $0.00 \pm 0.0$ & $0.00 \pm 0.00$ & 0.438 \\
\hline \multicolumn{7}{|c|}{ Embryo developmental stages (\%) } \\
\hline Morula & $50^{\mathrm{b}}(8 / 16)$ & $48^{\mathrm{b}}(12 / 25)$ & $76.2^{\mathrm{a}}(16 / 21)$ & $25^{c}(8 / 32)$ & - & 0.004 \\
\hline Early blastocyst & $25(4 / 16)$ & $40(10 / 25)$ & $23.8(5 / 21)$ & $50(16 / 32)$ & - & 0.175 \\
\hline Blastocyst & $0(0 / 16)$ & $12(3 / 25)$ & $0(0 / 21)$ & $0(0 / 32)$ & - & 0.361 \\
\hline $\begin{array}{l}\text { Expanded } \\
\text { blastocyst }\end{array}$ & $0^{\mathrm{b}}(0 / 16)$ & $0^{\mathrm{b}}(0 / 16)$ & $0^{\mathrm{b}}(0 / 21)$ & $15.6^{\mathrm{a}}(5 / 32)$ & - & 0.009 \\
\hline $\begin{array}{l}\text { Hatching } \\
\text { blastocyst }\end{array}$ & $0^{\mathrm{b}}(0 / 16)$ & $0^{\mathrm{b}}(0 / 16)$ & $0^{\mathrm{b}}(0 / 21)$ & $9.4^{\mathrm{a}}(3 / 32)$ & - & 0.044 \\
\hline
\end{tabular}

$a, b, c$ Within rows, means with different superscripts differ at $p<0.05$.

The number of recovered embryos was higher in groups $\mathrm{HM}$ and $\mathrm{HV}$ than in group $\mathrm{C}$ $(p<0.05)$, while group QM showed intermediate values and no embryos were collected at group QV. The development stages of embryos recovered $48 \mathrm{~h}$ post-insemination from does in groups C, HM, and QM were morula and early blastocyst stages. In contrast, 
embryo development was advanced in group HV since 15.6 and $9.4 \%$ of the embryos were expanded blastocyst and hatching blastocyst, respectively.

\subsection{In Vivo Assessment of Fertility and Productive Traits in Does Treated with GnRH-Loaded Nanoparticles}

The assessment in groups $\mathrm{C}, \mathrm{HM}$, and $\mathrm{HV}$ of the serum progesterone and estradiol concentrations $\left(\mathrm{P}_{4}\right.$ and $\mathrm{E}_{2}$, respectively) at 10, 17, and 24 days of pregnancy (Figure 7) showed higher $\mathrm{P}_{4}$ concentrations in group HM than in group HV $(p<0.05)$, with intermediate values in group $\mathrm{C}$. The interaction of treatment-by-time showed no differences among groups at day 10 but, from days 17 to $24, \mathrm{P}_{4}$ concentrations decreased in group $\mathrm{HV}$ and increased in group $\mathrm{HM}(p<0.05)$. The $\mathrm{E}_{2}$ concentrations were also affected by a treatment-by-time interaction $(p<0.05)$. There were no effects on days 10 and 17 , but the $\mathrm{E}_{2}$ concentrations at day 24 were higher in group HM than in groups HV and $\mathrm{C}(p<0.05)$. In fact, there were no changes over time in these groups whilst $E_{2}$ concentrations increased in group HM at day $24(p<0.05)$.

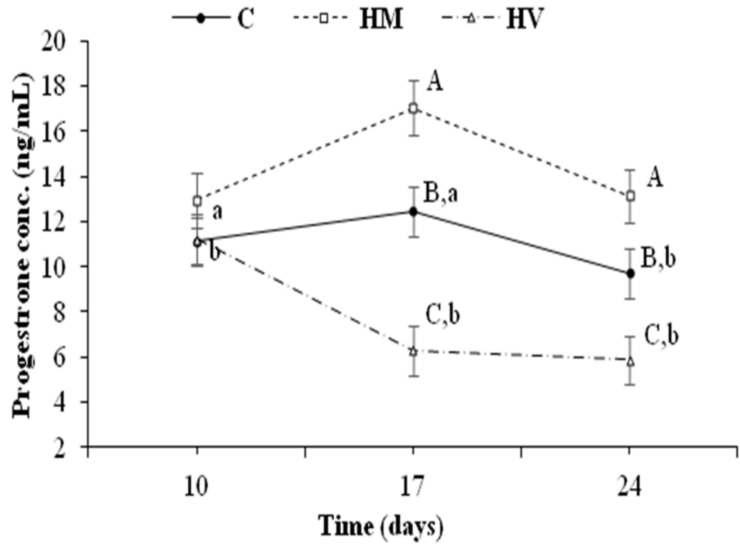

$$
\begin{gathered}
\mathrm{C}=11.10 \pm 1.09,{ }^{\mathrm{B}} \mathrm{HM}=14.37 \pm 1.2,{ }^{\mathrm{A}} \mathrm{HV}=7.42 \pm 1.09^{\mathrm{C}} \\
\mathrm{P}(\mathrm{Tr})=0.0013, \mathrm{P}(\mathrm{Tm})=0.024, \mathrm{P}(\operatorname{Tr} \times \operatorname{Tm})=0.019
\end{gathered}
$$

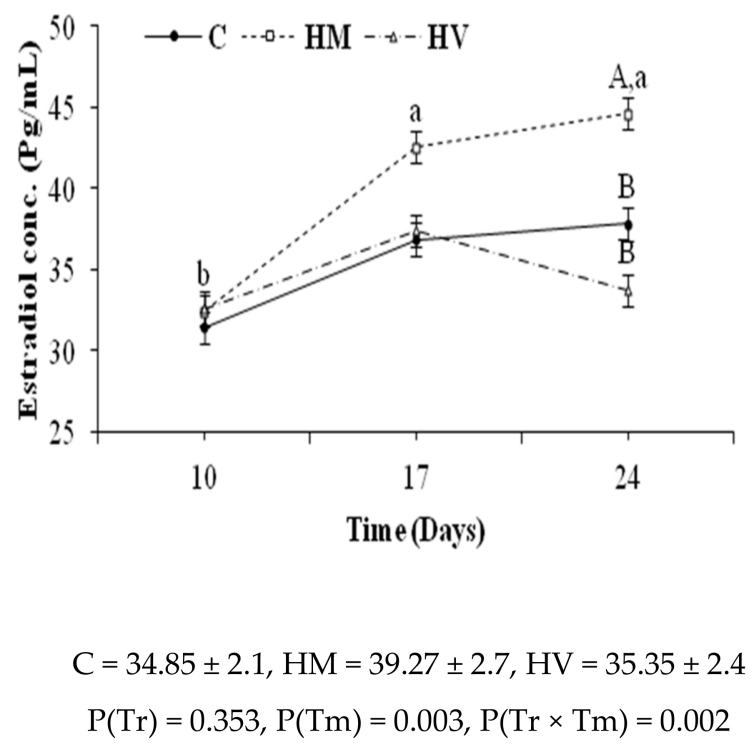

(B)

Figure 7. Changes over time in mean ( \pm S.E.M.) serum progesterone $(\mathbf{A})$ and $E 2$ concentrations $(\mathbf{B})$ in rabbit does receiving i.m. doses $(\mathrm{HM}=0.4 \mu \mathrm{g})$ or intravaginal doses $(\mathrm{HV}=4 \mu \mathrm{g})$ of $\mathrm{GnRH}-\mathrm{ChNPs}$ or bare $\mathrm{GnRH}(\mathrm{C}=0.8 \mu \mathrm{g})$. Overall values are included below the figure. $\mathrm{P}(\mathrm{Tr})$ accounts for treatment effects, $\mathrm{P}(\mathrm{Tm})$ for time effects, and $\mathrm{P}(\mathrm{Tr} \times \mathrm{Tm})$ for their interactions. Different uppercase and lowercase superscripts denote significant differences $(p<0.05)$ between or within treatments, respectively.

Groups $\mathrm{C}$ and HM showed significantly higher conception and parturition rates than group HV and, without differences among groups in the abortion rate, also showed higher litter size, number of living litters, viability rate, and total litter body-weight at birth $(p$ $<0.05$; Table 3). In contrast, group HV showed a higher number of dead litter and mean body-weight at birth than groups $\mathrm{C}$ and HM. 
Table 3. Productive traits of rabbit does receiving intramuscular $(\mathrm{HM}=0.4 \mu \mathrm{g})$ or intravaginal doses $(\mathrm{HV}=4 \mu \mathrm{g})$ of $\mathrm{GnRH}-\mathrm{ChNPs}$ or bare GnRH $(\mathrm{C}=0.8 \mu \mathrm{g})$.

\begin{tabular}{|c|c|c|c|c|}
\hline \multirow{2}{*}{ Variables } & \multicolumn{3}{|c|}{ Treatments ( $n=14$ Does/Group) } & \multirow{2}{*}{$p$-Value } \\
\hline & $\mathrm{C}$ & HM & HV & \\
\hline \multicolumn{5}{|c|}{ Fertility evaluation parameters ${ }^{1}$} \\
\hline Conception rate $(\%)$ & $78.5^{\text {a }}(11 / 14)$ & $71.5^{\mathrm{a}}(10 / 14)$ & $50^{\mathrm{b}}(7 / 14)$ & 0.019 \\
\hline Parturition rate $(\%)$ & $78.5^{a}(11 / 14)$ & $64.2^{a}(9 / 14)$ & $35.7^{\mathrm{b}}(5 / 14)$ & 0.050 \\
\hline Abortion rate $(\%)$ & $0.0(0 / 11)$ & $10.0(1 / 10)$ & $28.5(2 / 7)$ & 0.136 \\
\hline \multicolumn{5}{|c|}{ Pregnancy outcomes parameters (mean \pm S.E.M. $)^{2}$} \\
\hline Litter size at birth & $6.08 \pm 0.70^{\mathrm{a}}$ & $5.47 \pm 0.59^{\mathrm{a}}$ & $2.50 \pm 0.54^{b}$ & 0.001 \\
\hline No. of live litter & $6.08 \pm 0.70^{\mathrm{a}}$ & $5.47 \pm 0.59^{\mathrm{a}}$ & $1.92 \pm 0.63^{b}$ & 0.001 \\
\hline No. of dead litter & $0.00 \pm 0.00^{b}$ & $0.00 \pm 0.00^{b}$ & $0.54 \pm 0.29^{a}$ & 0.034 \\
\hline Viability rate at birth (\%) & $100^{a}$ & $100^{a}$ & $76.67^{\mathrm{b}}$ & 0.017 \\
\hline Litter weight at birth (g) & $60.5 \pm 3.4^{b}$ & $66.0 \pm 4.3^{\mathrm{ab}}$ & $76.0 \pm 6.8^{a}$ & 0.036 \\
\hline Total litter weight at birth (g) & $344.2 \pm 29.8^{\mathrm{a}}$ & $347.33 \pm 39.2^{\mathrm{a}}$ & $177.3 \pm 33.9^{b}$ & 0.003 \\
\hline
\end{tabular}

a,b Within rows, means with different superscripts differ at $p<0.05 .{ }^{1}$ Conception rate \%, (no. of pregnant does on Day 10/total no. of inseminated does $\times 100$ ); parturition rate $\%$, (no. of delivered does/no. of inseminated does $\times 100$ ); and abortion rate $\%$, (no. of aborted does $/$ no. of pregnant doe

$\times 100) .{ }^{2}$ Litter size at birth (no. of kids at birth / no. of kindling does) and viability rate at birth $\%(\mathrm{n}$

o. of live kids at birth/litter size at birth $\times 100$ ).

\section{Discussion}

The present study aimed to set the basis for implementing a nano-drug delivery system (i.e., GnRH-loading chitosan nanoparticles; GnRH-ChNPs) for improving procedures and yields of artificial insemination (AI) in rabbits by reducing hormone dose and facilitating animal handling during AI.

Achievement of these aims depends to a far extent on the physicochemical properties of the formula. The size of NPs is one of the most important determinants for passing barriers of mucosal tissues of and for the intracellular uptake [17]. The size range of most of the nanoparticles applied for the drug delivery system is between $50-250 \mathrm{~nm}$. This size allows the particles to pass efficiently through different barriers and cell pores, and thus improves the cellular uptake [18,19]. The biological efficiency of NPs greatly depends on the potential of the nano-carrier to conjugate with loaded molecules. Increasing loading efficiency of active molecules within carriers improves its lifetime in the bloodstream due to the protection from enzymatic degradation. In the present study, chitosan (Ch):TPP with a 2:1 ratio resulted in 90\% loading efficiency for GnRH (Table 1). In context, Hashem and Sallam [11] obtained 91.2\% LE when the same Ch:TPP ratio was used for GnRH (gonadorelin) encapsulation. On the other hand, Rather et al. [19] obtained 69\% LE for LH-RH when using the same Ch:TPP ratio in female fish.; Casares-Crespo et al. [10] also obtained only 43\% LE when they used a Ch:dextran ratio of 4:1 for GnRH encapsulation. These results confirm the appropriateness of selected preparation conditions and the formula (Ch concentration $1 \mathrm{mg} / \mathrm{mL}$ and Ch:TPP ratio 2:1) to conjugate most of the loaded hormone used in the present study.

In the present study, the addition of GnRH to ChNPs increased the particle size from $95.19 \pm 1.9 \mathrm{~nm}$ to $212 \pm 2.69 \mathrm{~nm}$ and decreased the zeta potential value from +34.0 to +8.0 $\mathrm{mV}$ (Table 1). Similar results have been obtained in previous studies by Kumari et al. [20], who found that the addition of trypsin increased the size of ChNPs from $147 \mathrm{~nm}$ to $\approx 220$ $\mathrm{nm}$. On the other hand, Hashem and Sallam [11] obtained a lower GnRH-ChNPs size after loading the $93.91 \pm 0.85 \mathrm{~nm}$ compound to non-loaded ChNPs of $125.9 \pm 3.06 \mathrm{~nm}$.

The variation in the size of nanoparticles after loading (increase or decrease) could be related to many factors including the type of loaded molecules, type of carrier molecules, the preparation conditions, and the surface charge (zeta potential). Kumari et al. [20] noted that the increased diameter of ChNPs after trypsin loading might be due to the size and the molecular weight of the enzyme during the loading process and adsorption on the 
ChNP surface. However, in our study, the increase in GnRH-ChNP size could be ascribed to the occurrence of aggregation between $\mathrm{GnRH}-\mathrm{ChNPs}$. This suggestion is confirmed by the decreased values of zeta potential (Table 1) and image taken by transmission electronic microscope (TEM), which clearly showed the aggregation between GnRH-ChNPs (Figure 3B.). Zeta potential refers to the value of surface charge and is considered as an indicator of particle stability. Regardless of the surface charge (+ or -$)$, high values of zeta potential $(>30 \mathrm{mV})$ refer to high stability and repulsion of the particles in the solution because the high value of the electrical double-layer thickness prevents the aggregation between the particles. Thus, a low value of zeta potential accelerates the process of particle aggregation [21,22]. However, the increase in zeta potential values improves the stability of nanoparticles, this effect may not be suitable for cell viability. High zeta potential value, particularly the positive charge, stimulates cellular uptake, which affects cell survival $[18,23]$.

The spectra of functional groups of $\mathrm{Ch}, \mathrm{ChNPs}$, and $\mathrm{GnRH}-\mathrm{ChNPs}$ presented in Figure 4 were recorded in the region between $4000 \mathrm{~cm}^{-1}$ to $400 \mathrm{~cm}^{-1}$. The Ch spectra showed peaks at $3458.3 \mathrm{~cm}^{-1}, 2924.3 \mathrm{~cm}^{-1}, 1645.5 \mathrm{~cm}^{-1}, 1419.1 \mathrm{~cm}^{-1}, 1314.8 \mathrm{~cm}^{-1}, 1572.05$ $\mathrm{cm}^{-1}$, and $1077 \mathrm{~cm}^{-1}$, which belong to the following functional groups: hydrogen-bond, $\mathrm{O}-\mathrm{H} ; \mathrm{C}-\mathrm{H}$ bond in pyranose rings; $\mathrm{C}=\mathrm{O}$ in $\mathrm{NHCOCH}_{3} ; \mathrm{C}-\mathrm{H}$ in $\mathrm{CH}_{2} \mathrm{OH} ; \mathrm{C}-\mathrm{N}$ stretching vibration of type II amine; $\mathrm{N}-\mathrm{H}$ band; and $\mathrm{C}-\mathrm{O}-\mathrm{C}$ in glucosidic-linkages. The addition of TPP to chitosan solution (ChNPs) resulted in the disappearance of $\mathrm{C}-\mathrm{H}$ and $\mathrm{N}-\mathrm{H}$ functional groups, indicating binding of these groups with phosphate groups in TPP. The addition of GnRH to ChNPs resulted in shifts for the remaining functional groups identified in the $\mathrm{Ch}$ spectra, which was confirmed in previous studies $[19,24,25]$.

The results of the in vitro release study showed an initial surge release of GnRH from $\mathrm{GnRH}-\mathrm{ChNPs}$ of around $50 \%$ during the first $10 \mathrm{~h}$ of incubation in phosphate buffer solution ( $\mathrm{PBS}, \mathrm{pH}=7.4$ ). This might be due to the weak bonds between adsorbed $\mathrm{GnRH}$ and the surface of ChNPs [26]. The other 50\% of conjugated GnRH was released slowly through the incubation time (from $10 \mathrm{~h}$ to $30 \mathrm{~h}$ ), which is due to the degradation of the GnRHChNPs' surface and the release of encapsulated GnRH [13]. In general, nanoparticles entrap, adsorb, bind, or encapsulate the active agents in their structure, depending on the preparation method [27]. The main use of the nano-formula innovated in the present study was the induction of ovulation in rabbit does. The preparation method used in our study seems to be suitable for this purpose, since the initial release of GnRH is required to stimulate the LH surge secretion, while the slow release maintains the GnRH concentration over a long period and this sustained the surge of gonadotrophins [28].

The assessment of the potential of the developed GnRH-ChNP formula for inducing the LH-surge and ovulation revealed the relevance of the HM, QM, and HV treatments. In these three treatments, a reduction from $25 \%$ to $50 \%$ in the conventional GnRH dose was achieved without negative effects on LH surge or ovulation rate. In contrast, the QV treatment failed to induce LH surge or ovulation. These results indicate the ability of the nano-formula to protect GnRH from enzymatic degradation [20], improving the cellular uptake and thus greater bioavailability.

It is interesting to note that HV treatment advanced the pre-implanted embryo development, as $25 \%$ of the collected embryos at $48 \mathrm{~h}$ post-treatment were beyond the blastocyst stage whilst morula and early blastocyst were the common stages in the other groups $(C$, $\mathrm{HM}$, and QM). In the present study, the loading efficiency of ChNPs for GnRH reached $90 \%$. Thus, intravaginal administration of GnRH-ChNPs may result in the sustained and high release of GnRH into the reproductive tract. This suggestion is highly acceptable since it is known that the mucus layer of the reproductive tract has a surface negative charge, whereas the GnRH-ChNPs developed in our study had a positive charge $(+8.0$ $\mathrm{mV})$. This difference in charge might increase the adhesion between the GnRH-ChNPs and the mucosal layer of the reproductive tract, allowing sustained GnRH release [11,29]. The sustained release of GnRH for a longer time may extend the ovulation time, leading to asynchrony of ova shed time. The variation in ovulation time might have resulted in 
the occurrence of fertilization for a longer period, and consequently a variation in embryo developmental stages. In context, it is worthy to note that GnRH is synthesized by preimplantation embryos in many species including rabbits [30]. Furthermore, GnRH has a pivotal role in the pre-implantation division and implantation of the embryo. Nam et al. [31] found that pre-implantation embryonic development could be enhanced by incubation with increasing concentration of the GnRH agonist, while GnRH antagonist had a deleterious effect. Thus, intravaginal deposition of GnRH may facilitate a GnRH binding with its receptors on preimplantation embryos, affecting their developmental stage.

Analysis of progesterone $\left(\mathrm{P}_{4}\right)$ and estradiol $\left(\mathrm{E}_{2}\right)$ throughout pregnancy revealed a clear reduction in $\mathrm{P}_{4}$ concentrations in group $\mathrm{HV}$ compared to groups $\mathrm{C}$ and HM. In rabbits, follicular and placental $E_{2}$ is the main luteotropic factor supporting $C L$ maintenance $[15,32]$. This explains the obvious increase in serum $\mathrm{P}_{4}$ concentration in group $\mathrm{HM}$, as $\mathrm{E}_{2}$ concentration was the highest among groups. On the other hand, the concentrations of $E_{2}$ showed a similar trend in groups $\mathrm{C}$ and $\mathrm{HV}$, which indicates the implication of other factors in the maintenance of $\mathrm{CL}$ and $\mathrm{P}_{4}$ concentration. In rabbits, the pre-implantation embryo can synthesize chorionic gonadotrophins, which play a role in the maternal embryo interface [33]. The failure of this process leads to luteolysis and early embryonic loss [34]. In the present study, a proportion of the embryos, about $25 \%$, of group HV had advanced developmental stages, while the rest of the embryos were at $48 \mathrm{~h}$ at the typical developmental stage. The lack of synchrony between advanced developed embryos and normally developed embryos might drive to a disturbance in the maternal-embryonic cross talking, leading to luteolysis, $\mathrm{P}_{4}$ reduction, and increased implantation failure and embryonic loss. Such hormonal and embryonic development disturbances may explain the lowest conception and parturition rates and litter size of group HV.

\section{Conclusions}

The fabrication of GnRH-ChNPs allows for a reduction in the conventional intramuscular GnRH dose used for AI in rabbits to half without affecting fertility. Conversely, the addition of GnRH-ChNPs to semen extenders, although successfully inducing ovulation, has negative impacts on fertility. Thus, more studies are needed to explore this point and allow further adjustments.

Author Contributions: Conceptualization, N.M.H. and E.M.H.; Methodology, E.M.H., N.M.H., and K.E.-D.M.E.-A.; Formal analysis and data curation, N.M.H. and E.M.H.; Writing-original draft preparation, E.M.H.; Writing-review and editing, N.M.H. and A.G.-B.; Supervision, N.M.H., K.E.D.M.E.-A., G.A.H., and M.H.S. All authors have read and agreed to the published version of the manuscript.

Funding: This research received no external funding.

Institutional Review Board Statement: The study was conducted according to the principles of animal care published by the European Union Directive 2010/63/UE on the protection of animals used for research and, in agreement, the experimental procedures used were previously assessed and approved by the INIA Committee of Ethics in Animal Research (report CEEA2014/087).

Conflicts of Interest: The authors declare no conflict of interest.

\section{References}

1. Boiti, C. Underlying physiological mechanisms controlling the reproductive axis of rabbit does. In Proceedings of the Proc.: 8th World Rabbit Congress, Puebla, Mexico, 7-10 September 2004; pp. 7-10.

2. Quintela, L.A.; Peña, A.I.; Vega, M.D.; Gullón, J.; Prieto, C.; Barrio, M.; Becerra, J.J.; García-Herradón, P.J. Reproductive Performance of Rabbit Does Artificially Inseminated via Intravaginal Administration of [des-Gly 10, d-Ala6]-LHRH Ethylamide as Ovulation Inductor. Reprod. Domest. Anim. 2009, 44, 829-833. [CrossRef] [PubMed]

3. Kumar, P.; Sharma, A. Gonadotropin-releasing hormone analogs: Understanding advantages and limitations. J. Hum. Reprod. Sci. 2014, 7, 170. [CrossRef]

4. Quintela, L.A.; Peña, A.I.; Vega, M.D.; Gullón, J.; Prieto, M.C.; Barrio, M.; Becerra, J.J.; Maseda, F.; García-Herradón, P.J. Ovulation induction in rabbit does submitted to artificial insemination by adding buserelin to the seminal dose. Reprod. Nutr. Dev. 2004, 44, 79-88. [CrossRef] [PubMed] 
5. Hashem, N.M.; Gonzalez-Bulnes, A. State-of-the-Art and Prospective of Nanotechnologies for Smart Reproductive Management of Farm Animals. Anim. 2020, 10, 840. [CrossRef]

6. Fakruddin, M.; Hossain, Z.; Afroz, H. Prospects and applications of nanobiotechnology: A medical perspective. J. Nanobiotechnology 2012, 10, 31. [CrossRef]

7. Rather, M.A.; Sharma, R.; Gupta, S.; Ferosekhan, S.; Ramya, V.L.; Jadhao, S.B. Chitosan-Nanoconjugated Hormone Nanoparticles for Sustained Surge of Gonadotropins and Enhanced Reproductive Output in Female Fish. PLoS One 2013, 8, e57094. [CrossRef]

8. Farokhzad, O.C.; Langer, R. Impact of Nanotechnology on Drug Delivery. ACS Nano 2008, 3, 16-20. [CrossRef]

9. Esquivel, R.; Juárez, J.; Almada, M.; Ibarra, J.; Valdez, M.A. Synthesis and Characterization of New Thiolated Chitosan Nanoparticles Obtained by Ionic Gelation Method. Int. J. Polym. Sci. 2015, 2015, 1-18. [CrossRef]

10. Casares-Crespo, L.; Fernández-Serrano, P.; Viudes-De-Castro, M.P. Protection of GnRH analogue by chitosan-dextran sulfate nanoparticles for intravaginal application in rabbit artificial insemination. Theriogenology 2018, 116, 49-52. [CrossRef] [PubMed]

11. Hashem, N.M.; Sallam, S. Reproductive performance of goats treated with free gonadorelin or nanoconjugated gonadorelin at estrus. Domest. Anim. Endocrinol. 2020, 71, 106390. [CrossRef]

12. Hassanein, E.M.; Hashem, N.M.; El-Azrak, K.M.; Hassan, G.A.; Salem, M.H. Effect of GnRH-loaded chitosan-TPP nanoparticles on ovulation induction and embryo recovery rate using artificial insemination in. In Proceedings of the 10th International Poultry Conference, Sharm El-Sheikh, Egypt, 26-29 November 2018.

13. Dounighi, N.M.; Eskandari, R.; Avadi; Zolfagharian, H.; Sadeghi, A.M.M.; Rezayat, M. Preparation and in vitro characterization of chitosan nanoparticles containing Mesobuthus eupeus scorpion venom as an antigen delivery system. J. Venom. Anim. Toxins Incl. Trop. Dis. 2012, 18, 44-52. [CrossRef]

14. Hashem, N.M.; Aboul-Ezz, Z.R. Effects of a single administration of different gonadotropins on day 7 post-insemination on pregnancy outcomes of rabbit does. Theriogenology 2018, 105, 1-6. [CrossRef]

15. Hashem, N.M.; Abo-Elsoud, M.; El-Din, A.N.; Kamel, K.; Hassan, G. Prolonged exposure of dietary phytoestrogens on semen characteristics and reproductive performance of rabbit bucks. Domest. Anim. Endocrinol. 2018, 64, 84-92. [CrossRef]

16. Statistical Analysis Systems, version 9.1; SAS Institute Inc.: Cary, NC, USA, 2004.

17. Panyam, J.; Labhasetwar, V. Biodegradable nanoparticles for drug and gene delivery to cells and tissue. Adv. Drug Deliv. Rev. 2012, 64, 61-71. [CrossRef]

18. Danaei, M.; Dehghankhold, M.; Ataei, S.; Davarani, F.H.; Javanmard, R.; Dokhani, A.; Khorasani, S.; Mozafari, M.R. Impact of Particle Size and Polydispersity Index on the Clinical Applications of Lipidic Nanocarrier Systems. Pharm. 2018, 10, 57. [CrossRef]

19. Gan, Q.; Wang, T.; Cochrane, C.; McCarron, P. Modulation of surface charge, particle size and morphological properties of chitosan-TPP nanoparticles intended for gene delivery. Colloids Surfaces B: Biointerfaces 2005, 44, 65-73. [CrossRef]

20. Kumari, R.; Gupta, S.; Singh, A.R.; Ferosekhan, S.; Kothari, D.C.; Pal, A.K.; Jadhao, S.B. Chitosan Nanoencapsulated Exogenous Trypsin Biomimics Zymogen-Like Enzyme in Fish Gastrointestinal Tract. PLoS ONE 2013, 8, e74743. [CrossRef]

21. Agarwal, M.; Agarwal, M.K.; Shrivastav, N.; Pandey, S.; Das, R.; Gaur, P. Preparation of Chitosan Nanoparticles and their In-vitro Characterization. Int. J. Life-Sciences Sci. Res. 2018, 4, 1713-1720. [CrossRef]

22. Honary, S.; Zahir, F. Effect of zeta potential on the properties of nano-drug delivery systems-a review (Part 1). Trop. J. Pharm. Res. 2013, 12, 255-264.

23. Barbari, G.R.; Dorkoosh, F.A.; Amini, M.; Sharifzadeh, M.; Atyabi, F.; Balalaie, S.; Tehrani, N.R.; Tehrani, M.R. A novel nanoemulsion-based method to produce ultrasmall, water-dispersible nanoparticles from chitosan, surface modified with cell-penetrating peptide for oral delivery of proteins and peptides. Int. J. Nanomed. 2017, 12. [CrossRef]

24. Loutfy, S.A.; Alam El-Din, H.M.; Elberry, M.H.; Allam, N.G.; Hasanin, M.T.M.; Abdellah, A.M. Synthesis, characterization and cytotoxic evaluation of chitosan nanoparticles: In vitro liver cancer model. Adv. Nat. Sci. Nanosci. Nanotechnol. 2016, 7, 035008. [CrossRef]

25. Badawy, M.E.I.; El-Nouby, M.A.M.; Marei, A.E.-S.M. Development of a Solid-Phase Extraction (SPE) Cartridge Based on ChitosanMetal Oxide Nanoparticles (Ch-MO NPs) for Extraction of Pesticides from Water and Determination by HPLC. Int. J. Anal. Chem. 2018, 2018. [CrossRef]

26. Amidi, M.; Romeijn, S.G.; Borchard, G.; Junginger, H.E.; Hennink, W.E.; Jiskoot, W. Preparation and characterization of proteinloaded N-trimethyl chitosan nanoparticles as nasal delivery system. J. Control. Release 2006, 111, 107-116. [CrossRef]

27. Lockman, P.R.; Mumper, R.J.; Khan, M.A.; Allen, D.D. Nanoparticle Technology for Drug Delivery Across the Blood-Brain Barrier. Drug Dev. Ind. Pharm. 2002, 28, 1-13. [CrossRef]

28. Mora-Huertas, C.E.; Fessi, H.; Elaissari, A. Influence of process and formulation parameters on the formation of submicron particles by solvent displacement and emulsification-diffusion methods: Critical comparison. Adv. Colloid Interface Sci. 2011, 163, 90-122. [CrossRef] [PubMed]

29. Cone, R.A. Barrier properties of mucus. Adv. Drug Deliv. Rev. 2009, 61, 75-85. [CrossRef]

30. Herrler, A.; Von Rango, U.; Beier, H.M. Embryo-maternal signalling: How the embryo starts talking to its mother to accomplish implantation. Reprod. Biomed. Online 2003, 6, 244-256. [CrossRef]

31. Nam, D.H.; Lee, S.H.; Kim, H.S.; Lee, G.S.; Jeong, Y.W.; Kim, S.; Kim, J.H.; Kang, S.K.; Lee, B.C.; Hwang, W.S. The role of gonadotropin-releasing hormone $(\mathrm{GnRH})$ and its receptor in development of porcine preimplantation embryos derived from in vitro fertilization. Theriogenology 2005, 63, 190-201. [CrossRef]

32. Keyes, P.L.; Wiltbank, M.C. Endocrine Regulation of the Corpus Luteum. Annu. Rev. Physiol. 1988, 50, 465-482. [CrossRef] 
33. Khan-Dawood, F.S.; Dawood, M. Chorionic gonadotropin receptors and immunoreactive chorionic gonadotropin in implantation of the rabbit blastocyst. Am. J. Obstet. Gynecol. 1984, 148, 359-365. [CrossRef]

34. Inskeep, E.K. Time-Dependent Embryotoxicity of the Endogenous Luteolysin Prostaglandin F2a in Ruminants. In Endocrine Toxicology, 3rd ed.; Informa UK Limited: London, UK, 2016; pp. 254-269. 